\title{
Posteromedial Release versus Ponseti Treatment of Congenital Idiopathic Clubfoot: A Long-Term Retrospective Follow-Up Study into Adolescence
}

This article was published in the following Dove Press journal: Therapeutics and Clinical Risk Management

\author{
Andrei Corbu $\mathbb{1}^{1,2}$ \\ Dan lonut Cosma ${ }^{1,3}$ \\ Dana Elena Vasilescu ${ }^{3}$ \\ Stefan Cristea ${ }^{2}$ \\ 'Department of Orthopedics and \\ Traumatology, Clinical Rehabilitation \\ Hospital Cluj-Napoca, Cluj, Romania; \\ ${ }^{2}$ Department of Orthopedics and \\ Traumatology, University of Medicine and \\ Pharmacy Carol Davila, Bucharest, \\ Romania; ${ }^{3}$ Department of Orthopedics- \\ Traumatology and Pediatric Orthopedics, \\ University of Medicine and Pharmacy luliu \\ Hatieganu, Cluj-Napoca, Cluj, Romania
}

Correspondence: Andrei Corbu Email corbuandrei@gmail.com
Purpose: Although many short-term studies have shown the superiority of Ponseti treatment to surgical treatment, studies with long-term follow-up of patients into adolescence are lacking. The aim of this study was to compare the morphological, functional and radiological results of the two methods into and during adolescent age, when both soft tissue and bony procedures can be performed to correct residual deformities.

Patients and Methods: We retrospectively evaluated two groups of patients diagnosed with congenital idiopathic clubfoot and treated with either the Ponseti method (34 clubfeet) and surgery in the form of posteromedial release (31 clubfeet). All included clubfeet were clinically fully corrected after initial treatment and final plaster removal. Evaluation was performed with the International Clubfoot Study Group (ICFSG) score.

Results: The age at follow-up was $12.8 \pm 1.6$ years in the Ponseti group and $13.5 \pm 1.7$ years in the surgical group. Excellent or good results were obtained in 26 feet $(76 \%)$ of the Ponseti group and in 14 feet $(45 \%)$ in the surgical group. The Ponseti treatment was significantly superior to posteromedial release in terms of the final score $(10.58 \pm 6.49$ versus $17.26 \pm 8.83$, $\mathrm{p}<0.001)$, functional score $(\mathrm{p}<0.001)$ and radiological score $(\mathrm{p}<0.001)$. Residual deformities were clinically present in both groups but were less frequent and less severe in Ponsetitreated patients. Flat-top talus was found to be present in both groups, but the Ponseti method was more protective than surgical treatment against this outcome (relative risk $=0.494$, $\mathrm{p}=0.002$ ). The overall foot and ankle mobility was significantly better in the Ponseti group $(\mathrm{p}<0.001)$.

Conclusion: The Ponseti method was superior to surgery for treatment of clubfoot and achieved better long-term morphological, functional and radiological results. It preserves better mobility of the foot and ankle, and results in less frequent and less severe residual deformities than surgical treatment.

Keywords: residual deformities, relapse, ICFSG score, adductus, calcaneocuboid, flat-top talus

\section{Introduction}

Congenital idiopathic clubfoot is a common congenital malformation, with a reported incidence of $1-7 \%{ }^{1,2}$ Although the pathological modifications present in clubfeet have been extensively described, and many etiological hypotheses have been proposed, its etiology remains unknown. ${ }^{3}$ This complex three-dimensional malformation is characterized by the presence of four deformities: equinus, varus, adductus and cavus. The purpose of any treatment, regardless of its nature, is to achieve a pain-free, functional, 
plantigrade foot. In the past, surgical treatment was the preferred method, and has been found to achieve good or satisfactory short-term results. ${ }^{4,5}$ In most cases, surgery is preceded by various forms of conservative therapy involving different massage, stretching, manipulation and immobilization techniques to correct the deformities. If different manipulation protocols do not completely correct the deformities, surgical interventions in the form of posteromedial release (PMR) or complete subtalar release are often necessary. The Ponseti method has become the gold standard, owing to its high correction rate and minimally invasive nature. ${ }^{6,7}$ Although superior outcomes have been reported with the Ponseti method on the short-term as well as in adults, longterm studies with follow-up into adolescence are lacking. We believe that evaluation of results during the intermediary age of adolescence may be helpful in understanding how the residual deformities and function of treated clubfeet evolve and also in improving the results in adulthood. There is also disparity between different scoring systems employed to evaluate clubfeet, which represents one of the reasons we chose the ICFSG score proposed by Bensahel to serve as a common language of evaluating clubfeet. ${ }^{8}$ The purpose of this retrospective study was to compare the long-term results of clubfeet treated in our clinic surgically with the PMR technique or conservatively with the Ponseti method.

\section{Patients and Methods}

We conducted a retrospective study on patients diagnosed with congenital idiopathic clubfoot who underwent either surgical treatment or conservative treatment with the Ponseti method in the Orthopedics-Traumatology Department of Rehabilitation Clinical Hospital ClujNapoca during 2003-2009, when our clinic was transitioning from surgical treatment to the conservative Ponseti treatment, and both methods were still used. After obtaining approval from the hospital's institutional review board (approval number 6/2019), we identified all patients diagnosed with congenital idiopathic clubfoot in the hospital's medical records and sent them invitations to participate in the study. Patients with syndromic and neuromuscular clubfeet, and patients who were initially treated in other hospitals and subsequently referred to our hospital were excluded. A total of 47 patients meeting our inclusion criteria were included after their legal guardians signed informed consent forms. The research was conducted in accordance with the Declaration of Helsinki. During the period of 2003-2009, one of the authors (DEV) performed surgery in all patients with clubfeet presenting to our clinic who did not respond to manipulative treatment, while another author (DIC) applied the Ponseti method exclusively. Patients were divided in two groups according to the treatment received.

The first group comprised 24 patients with 34 clubfeet, who underwent treatment with the Ponseti method. ${ }^{9}$ The mean age at treatment initiation was $2.8 \pm 1.5$ months. A percutaneous Achilles tenotomy (pAT) was performed in 31 feet $(91 \%)$ after correction of the cavus, adductus and varus deformities. Complete correction of the four deformities was initially achieved in all feet. After completion of the correction phase, patients were prescribed foot ankle abduction orthoses (FAO) and their parents were instructed to wear them according to the Ponseti protocol: 23 hours/day during the first 3 months and 16 hours/day during nighttime and naptime for the following 3 years.

The surgical group comprised 23 patients with 31 feet. These patients were initially managed conservatively with the manipulation and immobilization method described by Kite. ${ }^{10}$ When the results of this manipulative treatment reached a plateau, the residual deformities in these clubfeet were corrected with the PMR technique described by Turco. ${ }^{11}$ The mean age at surgery was 11.2 \pm 2.6 months. Postoperatively, all feet were immobilized in long leg plaster casts for 8 weeks. The plaster casts were routinely changed after the first 2 weeks to monitor postoperative wound healing. After the last plaster removal, customized FAO were used during naptime and nighttime for the following 2 years. Complete intraoperative correction was achieved in all feet according to the operative records.

As the Mitchell-Ponseti brace was not available in our country at the time of treatment, patients in both groups wore the same type of customized FAO, which had a similar design with the Steenbeek brace and maintained the treated clubfeet in $60^{\circ}-70^{\circ}$ external rotation and $10^{\circ}-15^{\circ}$ of dorsiflexion. In unilateral cases, the unaffected foot was held in $30^{\circ}-40^{\circ}$ of external rotation and $10^{\circ}-15^{\circ}$ of dorsiflexion.

Until follow-up, clubfeet recurred in 11 feet (32\%) in the Ponseti group and was treated by plaster casts and additional surgery when necessary, whereas 13 feet $(42 \%)$ in the surgical group underwent additional surgeries for correction of recurrence (Figure 1).

Patients included in the study were assessed with the International Clubfoot Study Group (ICFSG) score, which was developed to provide a common language for the examination of clubfeet and comprises a complex morphological, functional and radiological evaluation of clubfeet. ${ }^{8}$ The final 
score is the sum of the number of points obtained at each evaluation. Thus, treatment results can be classified into excellent (0-5), good (6-15), fair (16-30) or poor (>30). In addition to this score, radiological calcaneocuboid deformity was graded according to the classification proposed by Thometz. ${ }^{12}$ Dorsiflexion-plantar flexion, varus-valgus motion of the heel and supination-pronation of the forefoot were measured with a fluid level goniometer.

\section{Statistical Analysis}

Statistical analysis was performed in the IBM SPSS V25 program. The normality of distribution of quantitative variables was tested with the Kolmogorov-Smirnov test. Non-parametric (Mann-Whitney $U$-test) and parametric (Student's $t$-test and chi-square test) tests were used for data analysis, and $\mathrm{p}<0.05$ was considered the threshold for significance. Data linearity was determined with the Spearman correlation coefficient $\left(r_{s}\right)$. Quantitative variables were expressed as means and standard deviations.

\section{Results}

Forty-seven patients with a total of 65 clubfeet were included in the study (24 patients and 34 feet in the
Ponseti group, and 23 patients with a total 31 feet formed the surgical group). The male to female ratio was 1.18 in the Ponseti group and 1.55 in the surgical group. In patients treated with the Ponseti method, clubfoot was unilateral in 14 feet $(41 \%)$, whereas in surgically treated patients, 15 feet (48\%) had unilateral clubfoot. The mean age at follow-up was $12.8 \pm 1.6$ years in the Ponseti group and 13.5 years \pm 1.7 years for the surgical group (Table 1).

The mean final score was $10.58 \pm 6.49$ for the Ponseti group and 17.26 \pm 8.79 for the surgical group, and the difference was statistically significant $(\mathrm{p}<0.001)$. The age at treatment initialization did not influence the final results of the two groups $(p>0.05)$. A positive correlation was found between the morphological and functional $\left(r_{s}=0.456\right.$, $\mathrm{p}<0.01)$, morphological and radiological $\left(\mathrm{r}_{\mathrm{s}}=0.688\right.$, $\mathrm{p}<0.01)$, and functional and radiological $\left(\mathrm{r}_{\mathrm{s}}=0.620, \mathrm{p}<0.01\right)$ scores. Table 2 illustrates the distribution of the results.

The difference between the morphological scores obtained in the Ponseti group (3.26 \pm 2.14$)$ and the surgical group (4.16 \pm 2.34$)$ was not statistically significant $(p=0.128)$. Residual deformities, single or in association, were present in both groups, and were more frequent in the surgical group (Table 3). Adduction was the most common

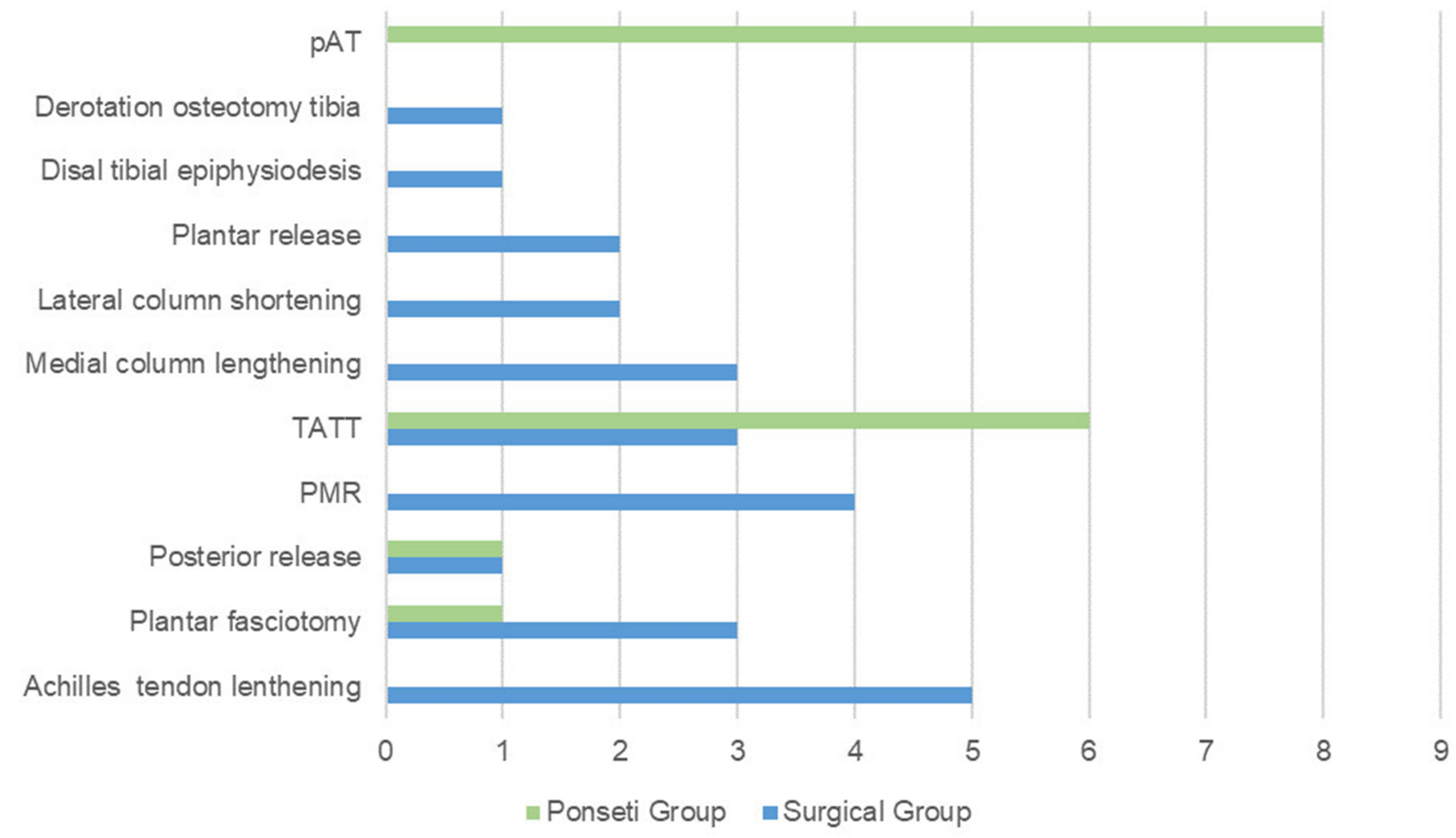

Figure I Revision surgery in both groups.

Note: Some feet underwent more than one procedure.

Abbreviation: TATT, tibialis anterior tendon transfer. 
Table I Demographic Data of Study Population

\begin{tabular}{|l|l|l|}
\hline & Ponseti Group & Surgical Group \\
\hline Number of patients & 24 & 23 \\
Number of feet & 34 & 31 \\
Male/female & $13 / 1 \mathrm{I}$ & $14 / 9$ \\
Unilateral & 14 & 15 \\
Mean age at follow-up & $12.8 \pm 1.6$ & $13.5 \pm 1.7$ \\
\hline
\end{tabular}

Table 2 Distribution of the Results in Both Groups Expressed in Number of Feet and Percentages

\begin{tabular}{|l|l|l|}
\hline Result & Ponseti Group & Surgical Group \\
\hline Excellent & $8(23.53 \%)$ & $1(3.23 \%)$ \\
Good & $18(52.94 \%)$ & $13(41.94 \%)$ \\
Fair & $7(20.59 \%)$ & $12(38.71 \%)$ \\
Poor & $1(2.94 \%)$ & $5(16.13 \%)$ \\
\hline
\end{tabular}

deformity in both populations (13 feet, or $38 \%$ in the Ponseti group, and 13 feet, or $42 \%$ in the surgical group). The morphological ICFSG scale classification of adduction was grade II in three feet $(9 \%)$ in the Ponseti group and six feet $(19 \%)$ in the surgical group. In both groups, a significant correlation was observed between the presence of adduction and calcaneocuboid radiological misalignment $\left(\mathrm{r}_{\mathrm{s}}=0.696, \mathrm{p}=0.000\right.$ in the Ponseti group and $\mathrm{r}_{\mathrm{s}}=0.859, \mathrm{p}=0.000$ in the surgical group). Despite the described correlation, isolated grade I calcaneocuboid joint deformity without clinically present adductus was observed in $12 \%$ of all feet included in this study. Residual cavus was present in 11 feet $(32 \%)$ in the Ponseti group (and was moderate in $64 \%$ of those 11), whereas 15 surgically treated feet $(48 \%)$ had this deformity (which was moderate in $40 \%$ of those 15 ). Equinus was moderate in all Ponseti-treated clubfeet with this deformity. A total of $32 \%$ of the surgically treated clubfeet had this deformity (which was severe in $30 \%$ of these feet). Recurrence of all four deformities was observed in three surgically treated clubfeet $(10 \%)$ and in one foot treated with the Ponseti method (3\%). The presence of flat-

Table 3 Distribution of Residual Deformities in Both Groups

\begin{tabular}{|l|l|l|}
\hline Deformity & Ponseti Group & Surgical Group \\
\hline Adduction & $13(38 \%)$ & $13(42 \%)$ \\
Cavus & $11(32 \%)$ & $15(48 \%)$ \\
Equinus & $5(15 \%)$ & $10(32 \%)$ \\
Varus & $2(6 \%)$ & $9(29 \%)$ \\
\hline
\end{tabular}

Notes: A foot may present more than one deformity.
Table 4 Significantly Better Range of Motion in Clubfeet Treated with the Ponseti Method

\begin{tabular}{|l|l|l|l|}
\hline Range of Motion & $\begin{array}{l}\text { Ponseti } \\
\text { Group }\end{array}$ & $\begin{array}{l}\text { Surgical } \\
\text { Group }\end{array}$ & Significance \\
\hline & $\begin{array}{l}\text { Mean }( \pm \\
\text { SD) }\end{array}$ & $\begin{array}{l}\text { Mean }( \pm \\
\text { SD) }\end{array}$ & \\
\hline $\begin{array}{l}\text { Dorsiflexion-plantar } \\
\text { flexion }\end{array}$ & $42.08 \pm$ & $27.64 \pm$ & $\mathrm{P}<0.01$ \\
Varus-valgus motion of & 12.55 & 13.09 & \\
the heel & $28.38 \pm$ & $20.09 \pm$ & $\mathrm{P}<0.01$ \\
Supination-pronation of & 4.48 & 7.67 & \\
the forefoot & $13.5 \pm$ & $25.77 \pm$ & $\mathrm{P}<0.01$ \\
\hline
\end{tabular}

top talus was also associated with the type of treatment: Ponseti treatment, compared with the surgical treatment, was found to be protective against the development of flattop talus compared to the surgical treatment (relative risk $=0.494, p=0.002$ ). In contrast, the surgical treatment was associated with a two-fold greater risk of inducing flat-top talus than the conservative treatment (relative risk $=2.025, \mathrm{p}=0.001$ ).

We found a statistically significant difference between the functional and radiological scores for the surgical group (7.7 $\pm 4.98,5.38 \pm 2.74)$ and Ponseti group (7.83 $\pm 3.13,3.41 \pm 2.43)$ in favor of the latter $(p<0.001)$.

Overall dorsiflexion-plantar flexion, varus-valgus motion of the heel and supination-pronation of the forefoot were also significantly better in the Ponseti group (Table 4).

\section{Discussion}

We preferred to use the ICFSG score because it considers the morphological, functional and radiological aspects of clubfeet, it does not excessively rely on subjectivity for each patient and it has good intraobserver and interobserver reliability. ${ }^{13}$ Although the clubfeet were evaluated with the original score, we believe that a slight modification to the functional score would be appropriate to give pain during daily activity greater weigh than pain during sports. To our knowledge, only few studies have compared the long-term results of surgical and conservative treatment by using the ICFSG score, but other studies using different evaluation parameters and scores have reported superior results in favor of the Ponseti method. ${ }^{14-16}$ In a longerterm follow-up study of patients into adult age, using the ICFSG score as assessment tool, Smith has reported similar outcomes in patients treated with the Ponseti method (good or excellent results in $80 \%$ of the feet, and fair or 
poor results in $20 \%$ of the feet). However, better results were achieved with the complete subtalar release in the surgical group (good or excellent results in $60 \%$ of the feet, and fair or poor results in $40 \%$ of the feet). ${ }^{17}$ Although a satisfactory result is not necessarily a bad result, we were disappointed with the percentage of satisfactory and poor results after PMR (55\%).

Although we did not find a statistically significant difference between the morphological scores, the residual clinical deformities were less frequent and less severe in patients treated with Ponseti method. We did however observe a greater proportion of forefoot adduction (38\%) and cavus deformities (32\%) among patients treated with the Ponseti method in comparison to other published results. ${ }^{18,19} \mathrm{An}$ explanation for the increased frequency of these deformities lies in the fact that the learning curve of the correction phase might not have been completed at the time of treatment. Adduction, which was moderate in most feet in this group, was the most frequent deviation and showed a good correlation with calcaneocuboid joint deformity. The radiological presence of this radiological deformity without associated clinical adduction can be partly explained by the abnormal development of the calcaneocuboid joint, owing to the intrinsic pathology of clubfoot in both groups. Another possible explanation may be that counterpressure was simultaneously applied both on the neck of the talus and the calcaneocuboid joint in the same time, thus pushing the cuboid medially. Nevertheless, we consider that clinical correction of cavus and adductus deformities are easier to achieve than correction of varus and equinus deformities and therefore we believe that the management of clubfeet during the maintenance phase might have also contributed to this aspect. During the time interval when the clubfeet were treated, we used a customized FAO to maintain correction of the clubfeet because the Mitchell brace was not available in our country. Even though the feet were held in $60^{\circ}-70^{\circ}$ of adduction and $10^{\circ}-15^{\circ}$ of dorsiflexion, those orthoses were more rigid and less well adapted to the children's feet, possibly leading to a decreased compliance rate and an increased recurrence rate. Although many authors investigated the relapses and residual deformities of treated clubfeet, the method of clinical assessment of adduction and cavus deformity is not frequently described and interobserver reproducibility regarding the morphological variables exists. This statement is supported by the research conducted by Munshi, who reported an excellent interobserver agreement for the assessment of varus and equinus deformity, moderate agreement for forefoot adduction and equinus and poor interobserver agreement for the assessment of forefoot inversion. ${ }^{20}$ Laaveg reported a mean value of forefoot adduction of $2.8^{\circ}$ in 104 clubfeet treated with the Ponseti method in a long-term follow-up study (less than $5^{\circ}$ in 97 feet, more than $5^{\circ}$ in 7 feet). ${ }^{21}$ Sætersdal found a mean foot adduction of $4^{\circ}$ in 160 clubfeet treated with the Ponseti method and followed-up for 8-11 years. ${ }^{15}$ According to the ICFSG score, we considered adduction moderate when the forefoot was deviated medially less than $10^{\circ}$ degrees, and severe when the medial deviation of the forefoot was greater than $10^{\circ}$. Cavus represents the increase of the longitudinal medial arch of the foot and in clubfeet, it results due to the plantar flexion of the first metatarsal. Depending on the position of the patient during clinical examination, the medial arch might also appear differently. For instance, if the patient is standing, the longitudinal medial arch may flatten, but it can also increase with extension of the metacarpophalangeal (MTP) joints. ${ }^{22}$ In case of the ICFSG score, cavus deformity is evaluated with the foot dorsiflexed and depending on the appearance of the medial longitudinal arch it can be rated moderate or severe. This method is subjective and might have contributed to the increased rate of cavus deformities reported in this study, particularly if there is some degree of associated extension of the first MTP joint during ankle dorsiflexion. Interestingly, Reimers described a gradual increase of the longitudinal medial arch during growth and reported that approximately $7 \%$ of the adolescents evaluated in his study had a high-arched foot. ${ }^{23}$ We do not consider that this proportion of high-arched feet in healthy adolescents explains the percentage of $32 \%$ residual cavus deformity, but we believe that the tendency of the foot arch to increase might gradually aggravate an underlying cavus deformity that was not detectable during the clinical evaluations that were periodically performed during maintenance phase. Since we were on the learning curve and the feet were evaluated with the Pirani score after the correction phase, according to which cavus is graded by taking into consideration the creases on the medial aspect of the foot, we believe that some relapsing cavus deformities might have remained undetected. ${ }^{24}$ In the surgical group, slight radiological undercorrection of the calcaneocuboid joint might still have been present during surgery, although the lateral border of the foot appeared clinically straight. We agree with Thometz who suggested that this radiological parameter is closely related to the adduction deviation of the forefoot. ${ }^{12}$ In addition, studies have shown that other radiological angles used to measure adduction in clubfeet (talo-first metatarsal angle and calcaneofifth metatarsal angle) have a high variance of their values and do not always have a statistically significant correlation with this deformity. ${ }^{18,25,26}$ An important difference was observed in 
the case of varus deformity, which the Ponseti method was more efficient in correction and prevention. Other studies investigating long-term surgical results in clubfeet have reported similar percentages of varus, after both posteromedial release surgery and comprehensive release surgery. ${ }^{27,28}$ Interestingly, Docquier, who has found residual varus in $40 \%$ of the clubfeet treated by PMR which were evaluated in patients at a mean age of 21 years and 6 months, has stated that slight deformity appears to bell well tolerated, as compared with valgus overcorrection, which is more frequently produced by resecting the interosseous talocalcaneal ligament during complete subtalar releases. ${ }^{29,30}$ In a 5- to 12-year follow-up study, Ponseti also observed a slight persistent varus in $11 \%$ of clubfeet treated with his method but he did not consider treatment necessary in those cases. ${ }^{31}$ In contrast, residual equinus, which was more frequent and more severe in the surgical group, is not compatible with a plantigrade foot.

Because children become increasingly active and engaged in sports activities during the adolescence, the better functional results and range of motion achieved with the Ponseti method is an important finding, particularly given that clubfeet have lower mobility and strength than normal feet, regardless of the treatment method. ${ }^{32}$ Besides the abnormal development of foot bones due to iatrogenic interference with their vascularization, we agree with other authors that the fibrotic tissue that results after surgery on the posteromedial aspect of the foot and ankle may further retract during growth and contribute to increased stiffness and recurrences. ${ }^{16,33}$

Our study has some limitations. First, we could not compare the initial severity scores between the two groups, because the clubfeet treated with the Ponseti method were valuated with the Pirani score, whereas the surgically treated clubfeet were evaluated using the Dimeglio score. ${ }^{34}$ Both scores present a certain degree of subjectivity and their capacity of predicting the final outcome is not supported by enough evidence. ${ }^{35}$ Secondly, although we considered we completed the learning curve for the correction phase of Ponseti treatment by the time the clubfeet were treated, we were probably lacking experience in the maintenance phase, which might have influenced the increased rate of the residual cavus and adductus deformities as a result of our management of relapses, which can be difficult to diagnose in early stages. ${ }^{36}$ Thirdly, even though we considered the ICFSG score appropriate for the evaluation of clubfeet because it is comprehensive and takes into consideration morphological, functional and radiological criteria, there is still some degree of subjectivity.

All four clubfoot deformities included in this study were completely corrected after the initial treatment, yet despite the initial correction and the use of AFO orthoses, we still found residual deformities in our long-term follow-up. This result was not unexpected because congenital clubfoot is known for its high recurrence rate. Some patients will require further corrective surgery but in adolescence, when bone and soft tissue surgery do not pose a great risk of interfering with foot development, more options are available than in younger children.

\section{Conclusion}

Although complete correction was initially obtained in both groups, residual deformities were present in patients treated with both methods at follow-up, but they were less frequent and severe in the Ponseti group. Long-term results clearly favored the Ponseti method, which resulted in better morphological, functional and radiological scores. In comparison to PMR, this conservative method of treatment achieved better overall ICFSG results and led to a higher percentage of good or excellent results, better mobility of the foot and ankle, less radiological bone abnormalities with the expense of less revision surgeries during childhood.

\section{Disclosure}

This study was funded by the University of Medicine and Pharmacy Carol Davila Bucharest, which was not involved in any of the stages from study design to article submission. The authors report no conflicts of interest in this work.

\section{References}

1. Wynne-Davies R. Family studies and aetiology of club foot. $J$ Med Genet. 1965;2(4):227-232.

2. McConnell L, Cosma D, Vasilescu D, Morcuende J. Descriptive epidemiology of clubfoot in Romania: a clinic-based study. Eur Rev Med Pharmacol Sci. 2016;20(2):220-224.

3. Corbu A, Cosma D, Vasilescu DE, Cristea S. Congenital Talipes equinovarus: current concepts and treatment. Rev Med Chir Soc Med Nat Iasi. 2017;121(4):745-751.

4. Centel T, Bagatur AE, Ogü "t T, Aksu T. Comparison of the soft-tissue release methods in idiopathic clubfoot. $J$ Pediatr Orthop. 2000;20:648-651. doi:10.1097/00004694-200009000-00019

5. Tabatabaei S, Haddadpour A, Mehdinasab SA. Results of posteromedial release in resistant Talipes Equinovarus (Club Foot). Pak J Med Sci. 2011;27(4):851-854.

6. Cosma DI, Vasilescu DE. Ponseti treatment for clubfoot in Romania: a 9-year single-centre experience. J Pediatr Orthop B. 2014;23 (6):512-516. doi:10.1097/BPB.0000000000000081

7. Colburn M, Williams M. Evaluation of the treatment of idiopathic clubfoot by using the Ponseti method. J Foot Ankle Surg. 2003;42 (5):259-267. doi:10.1016/s1067-2516(03)00312-0 
8. Bensahel H, Kuo K, Duhaime M, International Clubfoot Study Group. Outcome evaluation of the treatment of clubfoot: the international language of clubfoot. J Pediatr Orthop B. 2003;12(4):269-271. doi:10.1097/01.bpb.0000078720.48512.a5

9. Ponseti IV, Campos J. The classic: observations on pathogenesis and treatment of congenital clubfoot. 1972. Clin Orthop Relat Res. 2009;467(5):1124-1132. doi:10.1007/s11999-009-0721-1

10. Kite JH. Nonoperative treatment of congenital clubfoot. Clin Orthop Relat Res. 1972;84:29-38. doi:10.1097/00003086-197205000-00007

11. Turco VJ. Resistant congenital clubfoot: one-stage posteromedial release with internal fixation: a follow-up report of a fifteen-year experience. J Bone Joint Surg Am. 1979;61-A:805-814.

12. Thometz JG, Simons GW. Deformity of the calcaneocuboid joint in patients who have talipes equinovarus. J Bone Joint Surg. 1993;75A (2):190-195. doi:10.2106/00004623-199302000-00005

13. Celebi L, Muratli HH, Aksahin E, et al.; and International Clubfoot Study Group. Evaluation of treated clubfoot: assessment of interobserver and intraobserver reliability. J Pediatr Orthop B. 2006;15 (1):34-36. doi:10.1097/01202412-200601000-00007.

14. Church C, Coplan JA, Poljak D, et al. A comprehensive outcome comparison of surgical and Ponseti clubfoot treatments with reference to pediatric norms. $J$ Child Orthop. 2012;6(1):51-59. doi:10.1007/s11832-012-0387-1

15. Sætersdal C, Fevang JM, Bjørlykke JA, Engesæter LB. Ponseti method compared to previous treatment of clubfoot in Norway. A multicenter study of 205 children followed for 8-11 years. J Child Orthop. 2016;10(5):445-452. doi:10.1007/s11832-016-0760-6

16. Ippolito E, Farsetti P, Caterini R, Tudisco C. Long-term comparative results in patients with congenital clubfoot treated with two different protocols. J Bone Joint Surg [Am]. 2003;85-A:1286-1294.

17. Smith PA, Kuo KN, Graf AN, et al. Long-term results of comprehensive clubfoot release versus the Ponseti method: which is better? Clin Orthop Relat Res. 2014;472(4). 1281-1290.doi:10.1007/s11999. 013-3386-8

18. Cooper DM, Dietz FR. Treatment of idiopathic clubfoot. A thirty-year follow-up note. J Bone Joint Surg Am. 1995;77 (10):1477-1489. doi:10.2106/00004623-199510000-00002

19. Chand S, Mehtani A, Sud A, Prakash J, Sinha A, Agnihotri A. Relapse following use of Ponseti method in idiopathic clubfoot. J Child Orthop. 2018;12(6):566-574. doi:10.1302/1863-2548.12.180117

20. Munshi S, Varghese RA, Joseph B. Evaluation of outcome of treatment of congenital clubfoot. J Pediatr Orthop. 2006;26(5):664-672. doi:10.1097/01.bpo.0000229972.01436.eb

21. Laaveg SJ, Ponseti IV. Long-term results of treatment of congenital club foot. J Bone Joint Surg Am. 1980;62(1):23-31.

22. Welte L, Kelly LA, Lichtwark GA, Rainbow MJ. Influence of the windlass mechanism on arch-spring mechanics during dynamic foot arch deformation. $J$ R Soc Interface. 2018;15:20180270. doi:http://dx. doi.10.1098/rsif.2018.0270
23. Reimers J, Pedersen B, Brodersen A. Foot deformity and the length of the triceps surae in Danish children between 3 and 17 years old. $J$ Pediatr Orthop B. 1995;4(1):71-73. doi:10.1097/01202412199504010-00011

24. Pirani S, Outerbridge HK, Sawatzky B, Stothers K A reliable method of clinically evaluating a virgin clubfoot evaluation. 21st SICOT Congress. Sydney, Australia:1999.

25. Prasad P, Sen RK, Gill SS, Wardak E, Saini R. Clinico-radiological assessment and their correlation in clubfeet treated with postero-medial soft-tissue release. Int Orthop. 2009;33(1):225-229. doi:10.1007/s00264-007-0448-0

26. Ponseti IV, El-Khoury GY, Ippolito E, Weinstein SL. A radiographic study of skeletal deformities in treated clubfeet. Clin Orthop Relat Res. 1981;10(160):30-42.

27. Corbu A, Vasilescu DE, Andrei M, Cristea S. Radiological assessment of residual deformities of surgically treated idiopathic congenital clubfeet during early infancy. HVM Bioflux. 2019;11(3):95-99.

28. Kuo KN, Smith PA. Correcting residual deformity following clubfoot releases. Clin Orthop Relat Res. 2009;467(5). doi:1326-1333. doi:10.1007/s11999-008-0664-y

29. Docquier PL, Leemrijse T, Rombouts JJ. Clinical and radiographic features of operatively treated stiff clubfeet after skeletal maturity: etiology of the deformities and how to prevent them. Foot Ankle Int. 2006;27:29-37. doi:10.1177/107110070602700106

30. Thompson GH, Richardson AB, Weistin GW. Surgical management and resistant congenital talipes equinovarus deformities. J Bone Joint Surg Am. 1982;64(5):652-665.

31. Ponseti IV, Smoley EN. The classic: congenital club foot: the results of treatment. 1963. Clin Orthop Relat Res. 2009;467(5):1133-1145. doi:10.1007/s11999-009-0720-2

32. Eidelman M, Kotlarsky P, Herzenberg JE. Treatment of relapsed, residual and neglected clubfoot: adjunctive surgery. J Child Orthop. 2019;13(3):293-303. doi:10.1302/1863-2548.13.190079

33. Uglow MG, Clarke NM. Relapse in staged surgery for congenital talipes equinovarus. J Bone Joint Surg Br. 2000;82(5):739-743. doi:10.1302/0301-620x.82b5.9413

34. Diméglio A, Bensahel H, Souchet P, Mazeau P, Bonnet F. Classification of clubfoot. J Pediatr Orthop Part B. 1995;4 (2):129-136.

35. Jochymek J, Peterková T. Are scoring systems useful for predicting results of treatment for clubfoot using the ponseti method? Acta Ortop Bras. 2019;27(1):8-11. doi:10.1590/1413-78522019270 1189801

36. Ponseti IV. Relapsing clubfoot: causes, prevention, and treatment. Iowa Orthop J. 2002;22:55-56.
Therapeutics and Clinical Risk Management

\section{Publish your work in this journal}

Therapeutics and Clinical Risk Management is an international, peerreviewed journal of clinical therapeutics and risk management, focusing on concise rapid reporting of clinical studies in all therapeutic areas, outcomes, safety, and programs for the effective, safe, and sustained use of medicines. This journal is indexed on PubMed Central, CAS,
Dovepress

EMBase, Scopus and the Elsevier Bibliographic databases. The manuscript management system is completely online and includes a very quick and fair peer-review system, which is all easy to use. Visit http://www.dovepress.com/testimonials.php to read real quotes from published authors. 